\title{
Prevenção do afogamento com uso de conteúdos: Atitudinal, procedimental e conceitual
}

\section{Drowning prevention using content: Attitudinal, procedural and conceptual}

\author{
DOI: $10.46814 /$ lajdv3n6-018
}

Recebimento dos originais: 01/11/2021

Aceitação para publicação: 08/12/2021

\section{Marcelo Barros de Vasconcellos}

Marcelo Barros de Vasconcellos é professor Adjunto da Universidade do Estado do Rio de Janeiro (Brasil),

Especialista em atividades aquáticas, mestre em Saúde Coletiva, doutor pela Universidade Federal do Rio de Janeiro, membro da Sociedade Brasileira de Salvamento Aquático (SOBRASA) e da

Associação Ibero-Americana de Educação Aquática Especial e Hidroterapia (AIDEA),

Guarda vidas e Instrutor da Federação Internacional de Salvamento (ILS) e também autor do livro

Natação Monitorada: testes desde aquacidade até o nível avançado

E-mail: professormarcelobarros@hotmail.com

\section{Fernando Correa de Macedo}

Fernando Correa de Macedo é doutor e mestre em Educação pelo Programa de Pós-graduação em Educação da Universidade do Estado do Rio de Janeiro (ProPEd-UERJ)).

Professor assistente da Universidade do Estado do Rio de Janeiro (Brasil) lotado no Instituto de Aplicação Fernando Rodrigues da Silveira - CAp-UERJ e Professor do Centro Universitário Celso Lisboa

\section{RESUMO}

O afogamento é um problema de saúde pública universal que não recebeu a atenção necessária e impacta desproporcionalmente as crianças. Diversos fatores podem causar afogamento, por isso, existe a necessidade de se preveni-lo com o uso de conteúdos, não apenas procedimental, mas também atitudinal e conceitual. Objetivo deste texto foi refletir sobre as habilidades, conceitos e atitudes necessárias para a prevenção do afogamento e a respeito dos conteúdos procedimentais, atitudinais e conceituais que devem compor as aulas de natação de crianças para aumentar a segurança aquática. A metodologia foi de revisão bibliográfica com a base nas publicações de artigos disponíveis, nos últimos 10 anos, na base de dados Pub Med, com as palavras chaves: natação e afogamento. Os resultados mostraram que o conteúdo procedimental, que devem compor as aulas de natação de crianças para aumentar a segurança aquática, devem fazer com que o aluno aprenda a saber fazer, executar ações na água relacionadas ao desenvolvimento da aquacidade. Já os conteúdos conceituais devem fazer com que o aluno aprenda a saber sobre fatos, conceitos, símbolos, imagens, princípios materiais, e por fim os conteúdos atitudinais, o aluno aprenda a saber respeitar, conviver com normas, posturas, valores e atitudes. Pode-se concluir que o ensino da natação com os três conteúdos interligados (procedimental, conceitual e atitudinal) é mais uma ferramenta para ajudar a prevenir o afogamento. Os alunos precisam saber realizar a técnica procedimental para utilizar os braços e pernas com eficiência para sustentação e deslocamento, flutuar na vertical e horizontal, mudar de decúbito, conseguir se deslocar por alguns segundos em busca de local seguro, além disso, é importante também fornecer conteúdos para que ele possa adquirir conhecimento conceituais e desenvolver atitudes corretas, sobre os riscos de afogamento, aprender a ter controle emocional e discernimento em situações de perigo.

Palavras Chaves: afogamento, prevenção, natação. 


\begin{abstract}
Drowning is a universal public health problem that has not received the necessary attention and disproportionately impacts children. Several factors can cause drowning, so there is a need to prevent it with the use of content, not only procedural, but also attitudinal and conceptual. The objective of this text was to reflect on the skills, concepts and attitudes necessary for the prevention of drowning and on the procedural, attitudinal and conceptual contents that should be part of swimming lessons for children to increase water safety. The methodology was a bibliographic review based on the publications of articles available, in the last 10 years, in the Pub Med database, with the keywords: swimming, prevention and drowning. The results showed that the procedural content, which should be part of swimming lessons for children to increase water safety, should make the student learn to know how to do, perform actions in water related to the development of aquacity. The conceptual contents, on the other hand, must make the student learn to know about facts, concepts, symbols, images, material principles, and finally the attitudinal contents, the student learns to know how to respect, live with norms, postures, values and attitudes. It can be concluded that teaching swimming with the three interconnected contents (procedural, conceptual and attitudinal) is another tool to help prevent drowning. Students need to know how to perform the procedural technique to use their arms and legs efficiently for support and displacement, float vertically and horizontally, change position, be able to move for a few seconds in search of a safe place, in addition, it is also important to provide content so that he can acquire conceptual knowledge and develop correct attitudes about the risks of drowning, learn emotional control and discernment in dangerous situations.
\end{abstract}

Keywords: drowning, prevention, swimming.

\title{
1 INTRODUÇÃO
}

O ensino por competência atribui ao processo educacional uma capacidade de utilização prática daquilo que é ensinado. A articulação entre teoria e prática exige que o conteúdo ensinado adquira uma funcionalidade para o educando (ZABALA, 2014; PERRENOUD, 2000; DARIDO, 2007).

Uma competência reúne vários conhecimentos, habilidades e atitudes para sua perfeita execução. Nas tarefas motoras, entende-se que não basta desempenhar as habilidades motoras, mas que esse desempenho ocorra fundamentado em conceitos definidos e com as atitudes adequadas à sua implementação.

No caso da prevenção ao afogamento, as competências que devem ser desenvolvidas são múltiplas e extrapolam o ensino particular dos indivíduos.

O afogamento é considerado um "assassino global” que não recebeu a atenção necessária (BARCALA-FURELOS ET AL., 2019) e impacta desproporcionalmente as crianças (WILLCOXPIDGEON ET AL., 2020), grupo no qual o afogamento é $2^{\text {a }}$ causa de morte acidental (BARCALAFURELOS ET AL., 2019).

São fatores que contribuem para mortes por afogamento: as faltas de habilidades de natação e de consciência (LIN ET AL., 2019), os lapsos na supervisão de adultos (HAMILTON ET AL., 2019), as falhas nas barreiras nas áreas aquáticas (WHITWORTH ET AL., 2019) e a falta de treinamento ou 
de instruções referentes ao afogamento (BARCALA-FURELOS ET AL., 2019). Evitar o afogamento é um desafio à saúde pública (WILLCOX-PIDGEON ET AL., 2020) e uma preocupação universal (WHO, 2017).

Pesquisadores da China afirmam que um número significativo de mortes de crianças poderia ter sido evitado se os pais e outros parentes próximos estivessem mais preocupados com a segurança de seus filhos (LIU ET AL., 2019), que em muitos casos, se afogam enquanto nadam ou brincam próximo da água (WHITWORTH ET AL., 2019). De fato, no caso das crianças, são os pais que precisam manter a vigilância constante dos filhos e também são eles que podem, o quanto antes, matriculá-los em aulas de natação com foco na prevenção de afogamentos. Isto porque a intervenção preventiva de afogamento em crianças pode reduzir as taxas de mortalidade por esse tipo de acidente (LIU ET AL., 2019).

Uma das formas de prevenção de afogamentos em crianças é o ensino da natação com foco na redução de acidentes no meio líquido (VASCONCELLOS, 2020a). Nesse sentido, as aulas de natação e segurança aquática, em parte, reduzem o afogamento em crianças, além de permitir uma participação aquática saudável (WILLCOX-PIDGEON ET AL., 2020). As crianças são menos propensas a se afogar por terem participado de aulas de natação, portanto, as crianças devem ser ensinadas a nadar o quanto antes possível (BRENNER ET AL., 2009; WHO, 2017).

A natação é um esporte agradável que pode ajudar a manter a forma física e deve ser promovido (BOUGAULT ET AL., 2009). Aprender a nadar se apresenta como fator importante para enfrentar qualquer dificuldade que a criança tenha no meio líquido (SALOMEZ \& VINCENT, 2004), principalmente as com menos idades (MOSEK ET AL., 2020). No entanto, a natação ainda é subutilizada quando o aspecto é a prevenção de afogamentos em crianças (Vasconcellos, 2019). Pesquisadores da Austrália e Irlanda mencionam que crianças recebem educação insuficiente sobre segurança aquática em aulas de natação e não estão alcançando habilidades essenciais que ajudem a prevenir o afogamento (WILLCOX-PIDGEON ET AL., 2020).

Há uma série de habilidades que devem ser dominadas antes de uma criança ter capacidade total de nado (WILLCOX- PIDGEON ET AL., 2020), tais como: se envolver com a parte funda da piscina (QUAN ET AL., 2015); estar apta para vivenciar sozinha áreas aquáticas públicas (MOSEK ET AL., 2020) que, muitas vezes, são praias ou piscinas que as crianças já estão acostumadas a visitar rotineiramente (BARCALA-FURELOS ET AL., 2019); nadar uma certa distância; flutuar em decúbito dorsal; sustentar corpo na vertical com palmateios e; entrada e saída de segurança na água (STALLMAN ET AL., 2008). Além disso, é importante identificar a capacidade de natação das crianças e sua prontidão para lidar com circunstâncias difíceis em situações aquáticas (DAVEY ET AL., 2019). 
As aulas de natação devem incorporar uma ampla gama de competências em natação e segurança na água para garantir que as crianças tenham as habilidades necessárias para reduzir o afogamento, especialmente para aquelas consideradas em risco aumentado (WILLCOX-PIDGEON ET AL., 2020).

Por isso, pode haver uma necessidade significativa de aumento do nível de aulas de natação e educação sobre segurança na água para crianças (DAVEY ET AL., 2019). Essa educação pode vir em forma de adequada regulamentação de segurança para aulas de natação, educação dos pais e professores (AL-QURASHI ET AL., 2019) e avaliação diagnóstica (VASCONCELLOS ET AL., 2019) para ajudar a entender as limitações dos alunos iniciantes na natação que podem provocar acidentes infantis por afogamento.

Por mais que a ênfase de algumas escolas de natação não seja a prevenção de afogamentos, como mostrado no estudo de Willcox-Pidgeon et al. (2020), onde se verificou que as escolas de natação eram mais propensas a ensinar estilo livre (87\%) e costas $(83 \%)$ e menos propensos a ensinar habilidades de segurança na água, como flutuar na vertical com uso de braços e pernas (53\%) e recuperação de sobrevivência (46\%), há necessidade de que aulas de natação incluam, em seus conteúdos iniciais, a prevenção de afogamento com teste de aquacidade desde o primeiro dia de aula e acompanhamento das mudanças no decorrer dos meses para que, progressivamente, o aluno passe a aprender os nados de forma mais segura.

Assim, o objetivo deste texto é refletir sobre as habilidades, conceitos e atitudes necessárias para a prevenção do afogamento e os conteúdos procedimentais, atitudinais e conceituais que devem compor as aulas de natação de crianças para aumentar a segurança aquática.

\section{A NATAÇÃO + SEGURA}

No Brasil, para prevenir o afogamento, por meio das aulas de natação (VASCONCELLOS, 2004) foi criada uma metodologia de natação denominada natação + segura (VASCONCELLOS ET AL., 2017) que valoriza, primordialmente, a segurança do aluno e a adaptação plena dele ao meio líquido com melhora da aquacidade (VASCONCELLOS, 2019). Essa metodologia considera aquacidade como o grau de adaptação de uma pessoa ao meio líquido e suas condições de autossustentação, domínio da respiração aquática, deslocamento no ambiente aquático, consciência corporal e poucas chances de afogamento (VASCONCELLOS, 2019). Trata-se de abordagem que evidencia, nas aulas de natação, múltiplas ações que venham a prevenir o afogamento, traumas ou situações que prejudiquem a progressão pedagógica para o aprendizado dos quatro nados (VASCONCELLOS, 2020b). 
O fato de alguns alunos já chegarem no primeiro dia de aula com certa aquacidade, não significa que eles não necessitem de informações preventivas sobre como devem se comportar no meio líquido e, sobretudo, que estes não requerem atenção preventiva nas aulas.

Os benefícios das habilidades em natação e segurança na água, juntamente com a conscientização sobre o risco de afogamento, são fatores de proteção bem estabelecidos contra o afogamento (WILLCOX- PIDGEON ET AL., 2020).

\section{CONTEÚdOS PEDAGÓGICOS}

As aulas de natação + segura são alicerçadas no desenvolvimento de competências. Os conceitos, as habilidades e as atitudes necessárias às competências aquáticas são alinhadas aos conteúdos pedagógicos conceituais, procedimentais e atitudinais (PERRENOUD, 2014; BRASIL, 1998; ZABALA, 2014) na prevenção de afogamento. Segundo a Organização Mundial da Saúde (OMS) a natação deve ser ensinada como um componente de um programa que tem conteúdos voltados para habilidades de segurança na água, além de conhecimento e atitudes em relação à água (WHO, 2017).

Nesse sentido, o professor necessita selecionar os conteúdos que precisa ensinar para os alunos iniciantes na natação para que eles não se afoguem.

\section{CONTEÚDO CONCEITUAL}

No conceitual o aluno aprende a "saber sobre”, fatos, conceitos, símbolos, imagens, princípios materiais, como por exemplo, o que é perigoso? O que é raso/fundo e quais os cuidados em cada um destes espaços? Qual o significado da figura ou texto contido em uma determinada placa? Qual o melhor local para se banhar? Onde é escorregadio e quais os riscos? Quando ligar para chamar os serviços de emergência. No Brasil, o Serviço de Atendimento Móvel de Urgência (SAMU) - 192, ou Bombeiros - 193.

Este conteúdo pode ajudar na prevenção de afogamento ao trabalhar a conscientização do aluno (VASCONCELLOS ET AL., 2019) para que ele seja capaz de aplicar as habilidades aquáticas caso esteja em situação de perigo (GUPTA ET AL., 2019), tenha controle emocional para raciocinar qual a melhor opção a seguir, conheça os avisos de placas, tenha cuidado com ralos (GUPTA ET AL., 2019) e não tenha comportamentos de alto risco no ambiente aquático (LIN ET AL., 2019).

Nesse sentido, ressalta-se a importância de definir o conceito a ser aprendido para prevenir o afogamento, como por exemplo, o que saber, o que fazer em determinada situação. Então, posteriormente, esse conceito se pode determinar objetivos, escolher conteúdos e metodologia para consolidá-lo como um conceito a ser aprendido pelo aluno. 
O professor pode trabalhar, por exemplo, com o significado das cores da bandeira que ficam afixadas nas praias para indicar o grau de perigo atual do mar e o aluno aprender a discernir o risco de afogamento. A bandeira verde significa local apropriado a banho; a amarela, risco de afogamento; a vermelha, alto risco de afogamento e; a preta, área desprotegida de guarda vidas.

Figura 1: orientações da SOBRASA sobre o significado das cores das bandeiras em relação ao grau de perigo.

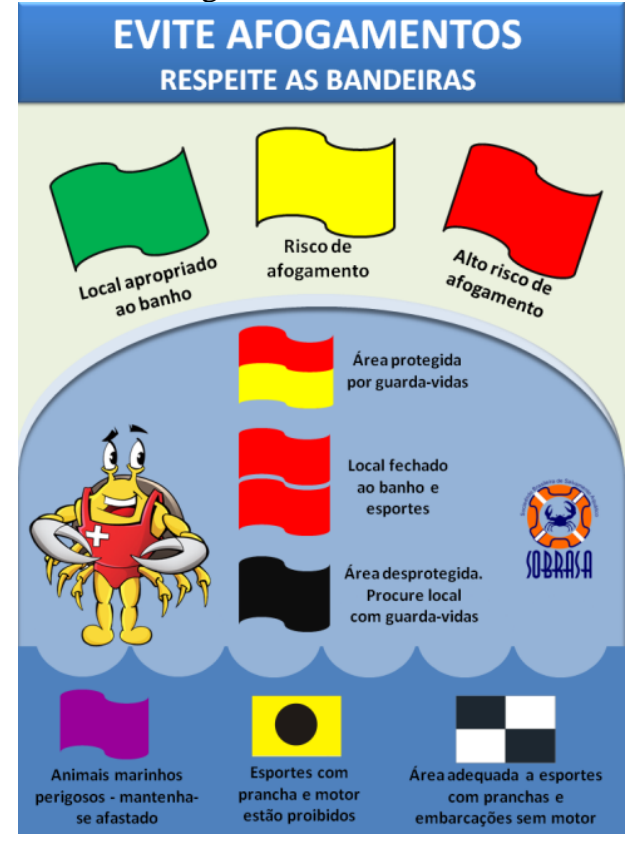

\section{CONTEÚDO ATITUDINAL}

Como conteúdo atitudinal, o aluno aprende a "saber respeitar, conviver" com normas, posturas, valores e atitudes, como por exemplo, saber respeitar as regras de utilização do ambiente aquático e do professor, adotar hábitos de prevenção de afogamento e/ou acidentes e, finalmente, interiorizar algo que será levado para toda a vida. Os conteúdos atitudinais apresentam-se como objetos de ensino e aprendizagem, e apontam para a necessidade de o aluno vivenciá-los de modo concreto no cotidiano escolar, buscando minimizar a construção de valores e atitudes por meio do currículo oculto (BRASIL, 1998).

Figura 2: orientações da SOBRASA sobre a prevenção de afogamento.

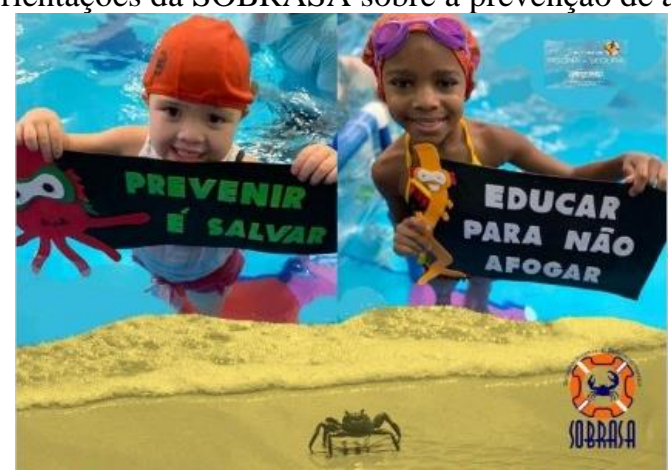


O professor pode trabalhar com as normas, valores e atitudes de utilização da piscina com foco nos cinco sentidos para prevenir afogamentos (VASCONCELLOS, 2020b). Ao usar a audição, o aluno vai ouvir sobre como ele deve se comportar para evitar acidentes. Já na visão, o aluno vai aprender a estar sempre no campo visual de um professor. Em relação ao tato, o aluno vai sentir que precisa estar em contato com o professor enquanto ele ainda não sabe nadar! Distância de um braço. No paladar, o aluno vai aprender a orientar os pais a não tomar bebida alcoólica se estiver pensando em entrar na água ou cuidando de alguém. Por fim, no olfato, o aluno estar atento ao cheiro forte de produtos químicos e de algo queimando.

Espera-se que o aluno consiga discernir e ter atitude de humildade para reconhecer, por exemplo, que mesmo sabendo nadar na piscina não tem habilidade para atravessar um rio nadando ou entrar no mar agitado etc.

Ao final de cada avaliação formativa o professor precisa verificar se houve mudança atitudinal, se o aluno ouviu sobre essas normas e comportamentos no ambiente aquático e colocou isso em prática, ou seja, se houve mudança de comportamento.

\section{CONTEÚDO PROCEDIMENTAL}

No conteúdo procedimental ele aprende a "saber fazer, executar", como por exemplo, os procedimentos adequados em cada item do teste de aquacidade (VASCONCELLOS ET AL., 2017), a fim de melhorar suas habilidades aquáticas.

O teste de aquacidade apresenta as diretrizes de conteúdos procedimentais que fundamentam as habilidades a serem dominadas pelo aprendiz. O uso do teste de aquacidade, no primeiro dia de aula, pode ajudar a identificar alunos não adaptados ao meio líquido e direcionar as aulas para melhorar o que se identificou com falta de competência aquática para que ele, progressivamente, se sinta mais confiante e melhore a sua aquacidade.

O teste é composto por 10 itens (figura 3) que avalia o grau de adaptação do aluno ao meio líquido, relacionados com domínio da respiração, flutuação, propulsão, mudanças entre decúbitos e palmateios. Os alunos realizam o teste individualmente e são avaliados por dois professores, um dentro e outro fora d'água, este último, faz o registro de cada item realizado. Quando o aluno consegue realizar sozinho a atividade proposta, em cada item, ele faz um (1) ponto e quando não o consegue é assinalado (0) para posterior categorização. O teste categoriza a aquacidade do aluno de acordo com a pontuação obtida, a saber, para aqueles que conseguem de zero a dois pontos como aquacidade muito fraca; de três a quatro pontos como fraca; de cinco a seis pontos como média; de sete a oito pontos como boa e; de nove a dez pontos, como aquacidade excelente (VASCONCELLOS ET AL., 2020). 
O diagnóstico da aquacidade no primeiro dia de aula possibilita que o professor de natação trabalhe com objetivos, de forma específica, para melhoria de cada componente das habilidades aquáticas básicas (conteúdo procedimental). Os outros dois conteúdos, conceituais e atitudinais, ajudam na construção de consciência sobre como lidar de forma preventiva no ambiente aquático e nunca subestimar o risco e superestimar a capacidade de nadar sendo imprudente no meio líquido.

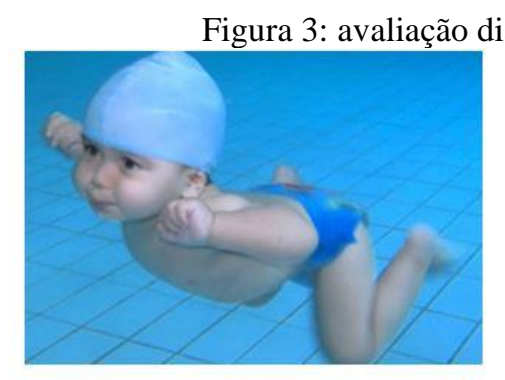

1

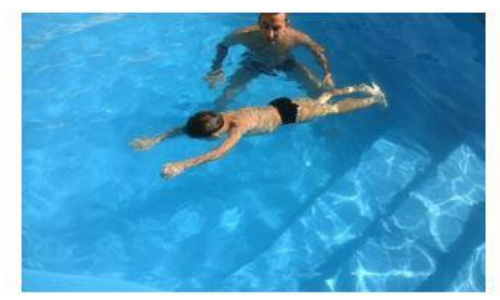

4

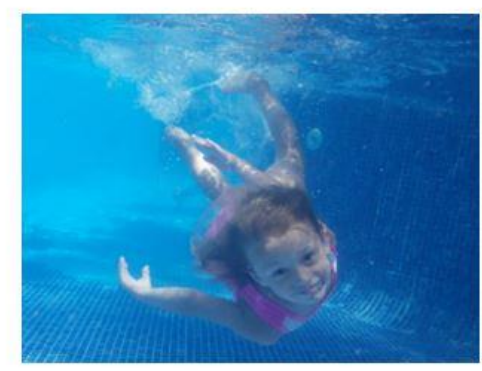

7

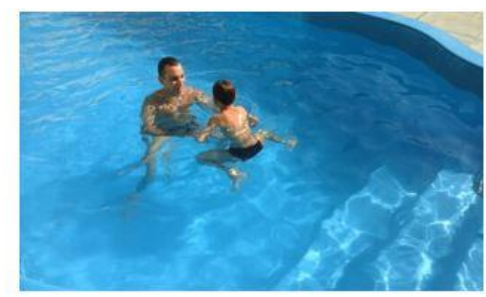

5 e 9

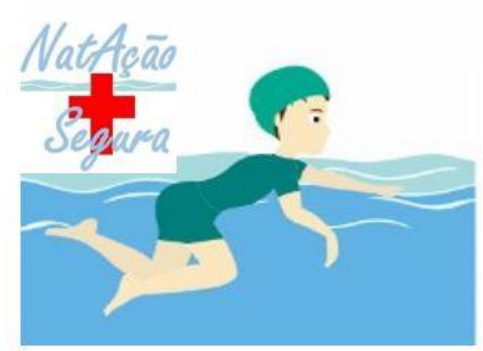

8

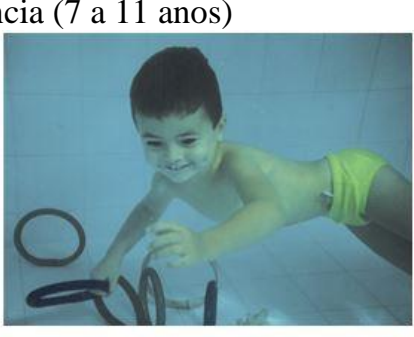

3

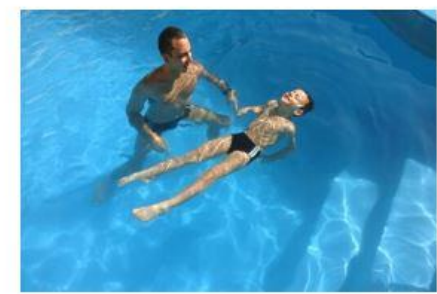

6

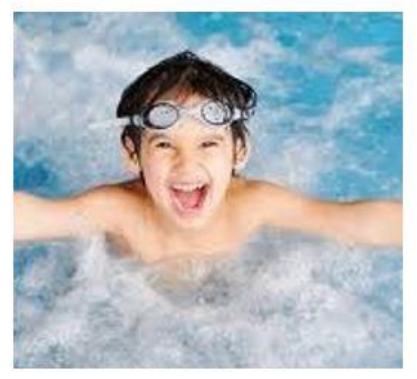

10

\section{DIAGNÓSTICO DA AQUACIDADE}

Os dez conteúdos procedimentais numerados, na figura 3, são apresentados a seguir com intuito de verificar se o aluno consegue realizar a atividade a ser testada.

A primeira verificação é para identificar se o aluno consegue realizar bloqueios da respiração embaixo d'água (apneia estática) por 10 segundos e repetir três vezes. A forma que o aluno reage ao colocar o rosto na água demonstra para o professor o quanto adaptado a este local ele está. Quem não está adaptado quer tirar logo o rosto da água, passa a mão no rosto, balança a cabeça, não consegue 
abrir os olhos. Ficar sem respirar momentaneamente com o rosto na água pode ser natural para um aluno e incômodo para outro, ou seja, este último requer uma adaptação a este local.

Prevenção de afogamentos no sistema educacional tem efeitos positivos em termos de reconhecimento de fatores desencadeantes de afogamentos em idades vulneráveis. Uma intervenção simples, mas bem orientada, é capaz de garantir aprendizado e retenção do que foi aprendido a médio prazo em crianças a partir dos cinco anos de idade (BARCALA-FURELOS ET AL., 2019).

A avaliação na água deve começar pela avaliação das habilidades de segurança da criança, especialmente da capacidade de expirar quando o nariz ou a boca, ou ambos, estiverem embaixo da água, ou pelo menos da capacidade de fechar e vedar a nasofaringe. Isso indica imediatamente os níveis de conforto e habilidade do aluno caso a sua face fique embaixo d'água.

A segunda é afundar a cabeça na água sem medo, soltar o ar (controle respiratório) por 5 vezes. Alunos precisam compreender que têm de soprar (expirar) quando sua boca e nariz vão para baixo d'água, não puxar o ar. É preciso verificar se os alunos ficaram atemorizadas ou assustados porque a sua face foi para baixo da água ou a água espirrou nela e inspirar acaba sendo um erro frequente que pode resultar em sufocação e tosse e até mesmo aumenta o medo da criança estar na água. Para a OMS, os programas de segurança aquática devem ensinar algumas habilidades / competências, dentre elas as habilidades respiratórias de colocar o rosto na água, submergir e soprar bolhas, prender a respiração e expirar em posição submerso (WHO, 2017).

Para Costa et al. (2015), a avaliação permite que o professor tome a decisão mais eficiente para que o aluno iniciante seja contemplado de forma adequada ao seu nível de competência. Posteriormente, o professor pode comparar com a anamnese e ver se o aluno relatou algum problema respiratório que possa estar associado a alguma dificuldade de realizar a expiração na água, seja pelo nariz ou boca, rápido, lento, soltar e bloquear antes de subir para inspirar e de repetir o item a ser testado. Além disso, o resultado ajudará a nortear o conteúdo a ser trabalhado nas aulas seguintes.

A terceira é afundar e apanhar objeto no fundo sem uso de óculos com um (1) objeto a um (1) metro profundidade. Para Vasconcellos (2019) a identificação do nível de adaptação visual no ambiente aquático permite que trabalhe focado para melhorar a qualidade da aprendizagem do nadar. O professor vai identificar se os olhos dão a direção para afundar ou se ele tenta tatear o fundo com olhos fechados para achar o objeto.

Uma vez que o aluno tenha alcançado a capacidade de controlar a sua respiração, ele sabe que pode também controlar a posição do seu corpo na água. Mantendo os pulmões cheios de ar, ele flutua mais alto na água. Quando os pulmões estão com menos ar, o seu corpo flutua mais embaixo d'água. Esse conhecimento e essa experiência ajudam a eliminar ou diminuir o medo da água. 
A quarta é mudar de decúbito dorsal para ventral por duas vezes. Diante de uma situação inesperada ou queda na piscina a pessoa precisa dominar as técnicas de mudança da posição onde o rosco encontra-se voltado para água, para uma posição de decúbito dorsal "barriga para cima" a fim de conseguir voltar a respirar, descansar e nadar, se assim decidir, de forma consciente, que é a melhor opção a tomar.

A quinta é mudar da posição vertical para horizontal sem colocar o pé no chão por duas vezes. Diante de alguma situação que gere desorientação na água, este item visa identificar se o aluno consegue mudar da posição de flutuação com pernadas e palmateios na vertical para a posição horizontal a fim de ajustar a posição do corpo para facilitar a natação, para visualizar melhor caminho a se deslocar na água para nadar ou vivenciar a melhor posição para descansar.

A sexta é flutuar decúbito dorsal sem auxílio de materiais por 30 segundos. Um dos itens de maior dificuldade nos alunos iniciantes é o item flutuação em decúbito dorsal. Dominar a flutuação é um dos pilares da natação e por isso consta no teste de aquacidade. Se o aluno souber usar o corpo a seu favor, com leve pernada, palmateios, descontração muscular, equilíbrio, calma, controle da respiração, ajuste do centro de flutuação e gravidade ele dificilmente irá se afogar, pois poderá ficar flutuando e aguardar por socorro ou se deslocar suavemente para um local seguro. De fato, para aumentar a segurança na água é preciso ensinar crianças a utilizar braços e pernas para flutuar na vertical (Willcox-Pidgeon et al. 2020).

A sétima é sustentar-se na vertical com uso de palmateio por 30 segundos. Para pesquisadores da França, Nova Zelândia e Austrália, o item sete, do teste de aquacidade, que solicita pernada para sustentar o corpo na vertical, é um conteúdo importante que pode ser trabalhado como uma habilidade de sobrevivência em muitos incidentes de afogamento, sobretudo porque esse comportamento permite que o indivíduo imerso mantenha a cabeça acima da água, o que evita a inspiração da água, permite que ele inspecione o ambiente e tome uma decisão sobre esperar pelo resgate ou nadar em segurança (SCHNITZLER ET AL., 2015). As crianças que são capazes de flutuar na água por 30 segundos têm menor taxas de afogamento fatal e por isso este conteúdo deve ser ensinado na natação (WHO, 2017).

Diagnosticar a eficiência da pernada de sustentação e palmateios são importantes e objetivos didáticos também em Bangladesch, onde instrutores de natação da comunidade usam este conteúdo e ensinam seus alunos a flutuar na água por 30 segundos em piscinas, adaptadas em lagoas, como forma de prevenção de afogamentos (GUPTA ET AL., 2019).

A oitava é utilizar os quatro membros como segmentos propulsivos na superfície até a borda por três metros. Semelhantemente, outro item que os alunos mostraram muita dificuldade, é o item oito que exige que eles realizem deslocamento na superfície usando braços e pernas. Esse deslocamento pode ser desde um nado rudimentar imitando um "cachorrinho" ou deslocamento usando propulsão 
dos membros superiores e inferiores de crawl, costas ou peito. O objetivo deste item do teste não é exigir o uso de técnica de deslocamento e sim analisar apenas se ele consegue se deslocar na superfície sem colocar os pés no chão, por uma distância de $3 \mathrm{~m}$ até a borda mais próxima. De fato, é importante que a criança saiba nadar uma certa distância (STALLMAN ET AL., 2008). Para Brenner et al. (2009), em pessoas com mais de quatro anos de idade, há maior probabilidade de se afogar se não consegue nadar continuamente por alguns segundos (BRENNER ET AL., 2009).

A nona é realizar deslocamento embaixo d'água (apneia dinâmica) por dois metros. Além de usar cada item do teste para avaliar o nível de aquacidade do aluno iniciante o resultado do teste ajuda a organizar o currículo das aulas inicias da natação para cada aluno. Sobretudo porque o resultado da avaliação do teste de aquacidade pode apontar as habilidades que o aluno não tem e que será o conteúdo a ser trabalhado. Cada item não atingido passa a ser um descritor daquilo que o professor pode fazer nas suas próximas aulas para melhorar a adaptação do aluno ao meio líquido.

A última é agachar, afundar em pé e saltar com as mãos fora d'água por duas vezes por dois metros na área da piscina onde é funda. De fato, é importante aprender a utilizar a parte funda da piscina (QUAN ET AL., 2015). Ao testar o aluno na parte funda da piscina é possível identificar se ele sabe controlar o corpo (soltar o ar para afundar e dar impulso no fundo) e a mente (não se apavora ao tirar os pés do chão), não entra em desespero quando é deslocado para uma parte funda da piscina. Para Davey et al. (2019), os testes de desempenho na natação podem ser benéficos na identificação de nadadores fracos e em risco de afogamento devido à falta de habilidade técnica e aqueles que lutam na água devido à aptidão inadequada. Assim, o teste poderia funcionar como uma triagem de condicionamento físico e de segurança, com o objetivo de melhorar os dois, o que possivelmente aumentaria os dois aspectos simbioticamente (DAVEY ET AL., 2019), além de servir para trabalhar de forma específica para melhoria de habilidades onde cada um tem limitação (QUAN ET AL., 2015).

\section{CONCLUSÕES}

O afogamento é causado por multifatores. Assim, o ensino da natação com os três conteúdos interligados (atitudinal, procedimental e conceitual) é mais uma ferramenta para ajudar a prevenir o afogamento.

A excelente competência no teste de aquacidade (procedimental), não representa que o aluno está a salvo do afogamento, pois podem lhe faltar conhecimentos e atitudes que o salvarão ou que impedirão de se afogar. Ademais, a "incompetência" no teste pode ser causada por algum fator conceitual ou atitudinal, para além da habilidade aquática em si.

O uso do teste procedimental, como forma de diagnóstico preventivo, permite identificar o nível de aquacidade no primeiro dia de aula, assim como, tornar cada vez mais, o progresso do aluno na 
natação algo mensurável, palpável e objetivo. No entanto, esses alunos precisam adquirir conhecimento conceituais e desenvolver atitudes corretas sobre os riscos de afogamento, aprender a ter controle emocional e discernimento em situações de perigo, saber utilizar os braços e pernas com eficiência para sustentação e deslocamento, progredir para o ensino dos quatro nados somente quando já tiverem dominado a respiração aquática, flutuação vertical e horizontal, mudanças de decúbito e conseguindo se deslocar por alguns segundos em busca de local seguro. A prevenção de afogamento nas aulas de natação começa fora d'água e deve ser mantida na água por meio de conteúdos pedagógicos: conceituais, procedimentais e atitudinais. 


\section{REFERÊNCIAS}

- Al-Qurashi, F.O., Yousef, A.A., Aljoudi, A., Alzahrani, S.M., Al-Jawder, N.Y., Al-Ahmar, A.K., Al-Majed, M.S., Abouollo, H.M. (2019). A Review of Nonfatal Drowning in the Pediatric-Age Group: A 10-Year Experience at a University Hospital in Saudi Arabia. Pediatr Emerg Care. 35(11):782-86.

- Barcala-Furelos, R., Carbia-Rodríguez, P., Peixoto-Pino, L., Abelairas-Gómez, C., RodríguezNúñez, A. (2019). Implementation of educational programs to prevent drowning. What can be done in nursery school? Med Intensiva. 43(3):180-82.

- Bougault, V., Turmel, J., Levesque, B., Boulet, L.P. (2009). The respiratory health of swimmers. Sports Med. 39(4):295-312.

- Brasil. (1998). Secretaria de Educação Fundamental. Parâmetros curriculares nacionais: Educação Física / Secretaria de Educação Fundamental. Brasília: MEC/SEF, 114p.

- Brenner, R.A., Taneja, G.S., Haynie, D.L., Trumble, A.C., Qian, C., Klinger, R.M., Klebanoff, M.A. (2009). Association between swimming lessons and drowning in childhood. A case-control study. Arch Pediatr Adolesc Med. 163(3):203-10.

- Costa, A.M., Costa, M.J., Marinho, D.A. (2015). Velocidade crítica em natação: uma revisão da literatura. Motricidade. 11(3)158-170.

- Darido, S.C., \& Souza Júnior, O.M. (2007). Para ensinar Educação Física: possibilidades de intervenção na escola. Campinas:Papirus.

- Davey, M., Callinan, S., Nertney, L. (2019). Identifying Risk Factors Associated with Fatal Drowning Accidents in the Paediatric Population: A Review of International Evidence. Cureus. 11(11):e6201.

- Gupta, M., Rahman, A., Baset, K., Ivers, R., Zwi, A.B., Hossain, S., Rahman, F., Jagnoor, J. (2019). Complexity in Implementing Community Drowning Reduction Programs in Southern Bangladesh: A Process Evaluation Protocol. Int. J. Environ. Res. Public Health. 16(6):968.

- Hamilton, K., Peden, A.E., Smith, S., Hagger, M.S. (2019). Predicting pool safety habits and intentions of Australian parents and carers for their young children. J Safety Res. 71,285-94.

- Lin, C., Wang, L., Lu, T. (2019). Changes in drowning mortality rates and quality of reporting from 2004-2005 to 2014-2015: a comparative study of 61 countries. BMC Public Health; 19:1391.

- Mosek, D.P., Sperhake, J.P., Edler, C., Püschel, K., Schröder, A.S. (2020). Cases of asphyxia in children and adolescents: a retrospective analysis of fatal accidents, suicides, and homicides from 1998 to 2017 in Hamburg, Germany. International Journal of Legal Medicine; 134:1073-81.

- Perrenoud, P. (2000). Dez novas competências para ensinar. Artmed.

- Quan, L., Ramos, W., Harvey, C., Kublick, L., Langendorfer, S. (2015). Toward defining water competency: an American Red Cross definition. Int J Aquatic Res. 9(1):12-23. 
- Salomez, F., Vincent, J. (2004). Drowning: a review of epidemiology, pathophysiology, treatment and prevention. Resuscitation. 63(3):261-8.

- Schnitzler, C., Button, C., Croft, J.L., Seifert, L. (2015). A New Qualitative Typology to Classify Treading Water Movement Patterns. Journal of Sports Science and Medicine. 14(3):530-35.

- Stallman, R.K., Junge, M., Blixt, T. (2008). The teaching of swimming based on a model derived from the causes of drowning. Int J Aquatic Res. 2(4):372-82.

- Vasconcellos, M.B, Santos, R.O. (2004). Um estudo sobre o auto-salvamento nas aulas de natação, para crianças de 4 a 6 anos, como conteúdo auxiliar na prevenção de afogamentos. Revista Sprint. Ano XXI, nº134, p.43-47.

- Vasconcellos, M.B. (2019). Natação Monitorada. Testes desde aquacidade até o nível avançado. Rio de Janeiro: Paco.

- Vasconcellos, M.B. (2019). Teste de aquacidade para natação monitorada. Revista Saúde Física \& Mental. SFM. 7(1):1-6.

- Vasconcellos, M.B. (2020a). Natação + Segura. Revista Empresário Fitness \& Health. Edição 87. Março. Disponível em: https://revistaempresariofitness.com.br/atividades-aquaticas/natacaosegura/

- Vasconcellos, M.B. (2020b). Qual o dia de prevenir afogamentos? Revista Empresário Fitness \& Health. Edição 95. Novembro de 2020. Disponível em: https://revistaempresariofitness.com.br/atividades-aquaticas/qual-o-dia-de-prevenir-afogamentos/.

- Vasconcellos, M.B., Szpilman, D., Queiroga, A.C. Mello, D. (2017). Swim + safe: test for diagnostic evaluation and monitoring of water skills of beginner students. World conference on drowning prevention. Canada: Vancouver.

- Whitworth, H.S., Pando, J., Hansen, C., Howard, N., Moshi, A., Rocky, O., Mahanga, H., Jabbar, M., Ayieko, P., Kapiga, S., Grosskurth, H., Watson-Jones, D. (2019). Drowning among fishing communities on the Tanzanian shore of lake Victoria: a mixed-methods study to examine incidence, risk factors and socioeconomic impact. BMJ Open. 9(12):e032428.

- WHO. (2017). Preventing drowning: an implementation guide. Geneva: World Health Organization.

- Willcox- Pidgeon, S.M., Franklin, R.C., Leggat, P.A. Devine, S. (2020). Identifying a gap in drowning prevention: high- risk populations. Inj Prev 26(3):279-88.

- Willcox-Pidgeon, S., Kool, B. Moran, K. (2018) Perceptions of the risk of drowning at surf beaches among New Zealand youth. Int J Inj Contr Saf Promot. 25(4):365-71.

- Zabala, A., Arnau, L. (2010). Como aprender e ensinar competências. Artmed: Porto Alegre. 